\title{
Milliliter Per Minute Times One Hundred Milliliters
}

National Cancer Institute

\section{Source}

National Cancer Institute. Milliliter Per Minute Times One Hundred Milliliters. NCI

Thesaurus. Code C130191.

A unit of flow rate expressed as the number of milliliters per number of minutes times a unit of volume equal to 100 milliliters. 